\begin{abstract}
Iranica
Abstracta Iranica Revue bibliographique pour le domaine irano-aryen

Volume 34-35-36 | 2017

Comptes rendus des publications de 2011-2013
\end{abstract}

\title{
Avraham Faust, Hayah Katz. Survey, Shovel Tests and Excavations at Tel ${ }^{c}$ Eton: On Methodology and Site History
}

\section{Astrid Nunn}

\section{(2) OpenEdition \\ Journals}

Édition électronique

URL : http://journals.openedition.org/abstractairanica/41634

DOI : 10.4000/abstractairanica.41634

ISSN : 1961-960X

Éditeur :

CNRS (UMR 7528 Mondes iraniens et indiens), Éditions de l'IFRI

Référence électronique

Astrid Nunn, "Avraham Faust, Hayah Katz. Survey, Shovel Tests and Excavations at Tel ' Eton: On Methodology and Site History », Abstracta Iranica [En ligne], Volume 34-35-36 | 2017, document 62, mis en ligne le 15 juillet 2016, consulté le 04 octobre 2020. URL : http://journals.openedition.org/ abstractairanica/41634; DOI : https://doi.org/10.4000/abstractairanica.41634

Ce document a été généré automatiquement le 4 octobre 2020.

Tous droits réservés 


\section{Avraham Faust, Hayah Katz. Survey, Shovel Tests and Excavations at Tel ${ }^{c}$ Eton: On Methodology and Site History}

\section{Astrid Nunn}

\section{RÉFÉRENCE}

Avraham Faust, Hayah Katz. « Survey, Shovel Tests and Excavations at Tel cEton: On Methodology and Site History ». Tel Aviv, 39, 2012, p. 158-185.

Tel 'Eton est un site localisé dans la plaine de la Shéphélah à $3 \mathrm{~km}$ au nord de Tell Beit Mirsim. Plus de 1000 tessons de céramique de col de jarres ont été collectés durant la prospection du site. La plupart d'entre eux remonte au Fer II, et quelques-uns à l'époque achéménide. C'est dans la moitié nord (Lower mound) que ces derniers sont le plus fréquents. L'ouverture de petites tranchées (shovel test) n'a pas permis cette fois ci de mettre de l'architecture perse au jour (cf. c.r. Avraham Faust, « The Excavations at Tel ‘Eton (2006-2009): A Preliminary Report », PEQ 143/3, 2011, 198-224).

\section{AUTEURS}

\section{ASTRID NUNN}

Université de Munich 